\title{
The Effective Transmission of Acquired Sensor data with FFT, DWT and DTCWT in Different Channel Environment
}

\author{
Naveen H, Chetan H, Bhimsen Kulkarni, Sudatta Mohanty, Druva Kumar S, \\ Sreerama Reddy G M
}

\begin{abstract}
The paper describes the analysis of FFT, DWT and DTCDWT for effective transmission of acquired underwater sensor data in AWGN and Acoustic channel. The underwater temperature is acquired using a temperature sensor, $p H$ value is acquired using $\mathrm{pH}$ sensor, and Depth of water is acquired using ultrasonic sensor. The sensor data is acquired using ARM Cortex M4 Microcontroller and the same data is processed using FFT, DWT and DTCDWT in AWGN channel and Acoustic channel for comparative analysis. Number of Samples is limited to 64 samples and SNR values ranging from 0 to 50 are considered for analysis. Graphical user interface is designed using MATLAB and the simulation results shows that number of errors after transmission in FFT is more compared to DWT and also number of errors is decreased in the case of DTCDWT.
\end{abstract}

Index Terms: Acoustic Channel, DWT, DTCDWT, FFT

\section{INTRODUCTION}

The underwater data acquisition system and effective transmission of the acquired data is essential nowadays. The information gathered from the underwater are mineral exploration, temperature measurement, marine life exploration, assessing quality of water and underwater depth. Typically, underwater sensors will be placed inside an remotely operated vehicle which consumes very less power. The sensors data will be collected from ROV will be sent to the Central Data Acquisition unit located on the ground. The central data acquisition unit is also used to transmit the acquired data to remote unit efficiently.

Contamination of underwater can impact marine life and also human life. Clean up of contaminated groundwater tends to be very costly. Effective remediation of underwater is generally very difficult [1]. Determining the water level of a water reservoir is not an easy job to do as the water runs around $90 \mathrm{~m}-450 \mathrm{~m}$. below the surface. Also the traditional

Revised Manuscript Received on July 10, 2019.

Naveen H, Department of Electronic and Communication, New Horizon College of Engineering, Bangalore, Karnataka India.

Chetan H, Department of Electronic and Communication, C M R Institute of Technology, Bangalore, Karnataka India.

Bhimsen Kulkarni, Department of Electronic and Communication, New Horizon College of Engineering, Bangalore, Karnataka India.

Sudatta Mohanty, Department of Electronic and Communication, C M R Institute of Technology, Bangalore, Karnataka India.

Druva Kumar S, Department of Electronics and Communication, DSCE, Bangalore, Karnataka, India

Dr.Sreerama Reddy $\mathbf{G} \mathbf{M}$, Department of Electronics and Communication, CBIT,Kolar, Karnataka India methods involved in measuring water level like using a scale and chalk provides very inaccurate reading of the level or just a rough estimate of the water level. One of the major concern is also that a person has to be at the water reservoir site in order to perform the level and contamination measurement which is very time and cost consuming and quite impractical method.

\section{DETAILED DESIGN}

The purpose of detailed design is to divide the top module into small module as per the behavior of the system. The detailed design which is presented includes data flow diagram, system architecture, design consideration.

\section{A. Design Consideration}

System design identifies the modules that should be in the system, As per the requirements of this project, it is essential to identify water sensors that can provide real-time reading of water level and its contamination. Since the sensors will be installed on ROV it will be very difficult to transmit the data at very high speed to the base station directly therefore methods like efficient OFDM with good modulation technique are required to transmit data to the surface before transmitting to the base station. The OFDM technique uses FFT block which produces more errors. Hence more efficient techniques like DWT and DTCDWT block is replaced in OFDM block for efficient transmission of acquired underwater sensor data.

\section{B. Development Methods}

The figure below shows the top level block diagram of sensor data processing system wherein the temperature data, $\mathrm{pH}$ sensor data and depth information which is acquired will be processed using FFT, DWT and DTCDWT and sent into AWGN channel and Acoustic channel for comparative analysis. 


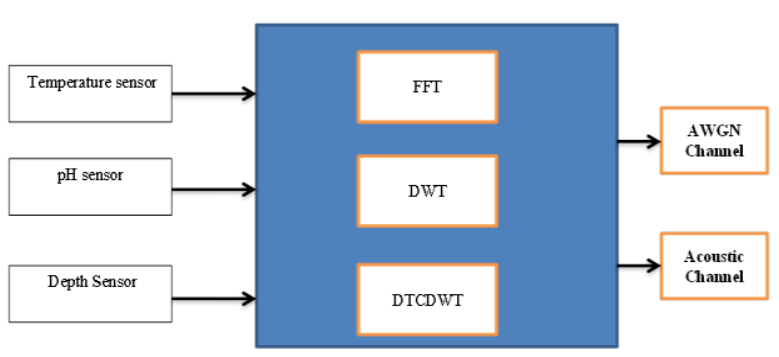

Fig. 1. Top level Block Diagram of Sensor Data Processing System

\section{IMPLEMENTATION}

The large system consists of Sensor data Acquisition unit, Sensor data transmission unit and two Channel proposed architecture was implemented using PSOC 5LP board [2], it was little costlier for the complete project implementation. The same architecture is implemented using ARM Cortex M4 (STM 32 board). The system architecture includes Sensor data acquisition unit, sensor Figure 2 and figure 3 shows the sensor data transmission unit, FFT/IFFT based Sensor data transmission unit in AWGN and Acoustic channel.

The Temperature sensor data, $\mathrm{pH}$ sensor data and Depth sensor data for one hour duration is acquired using STM32 board (ARM Cortex M4 Board) which is recorded in the table below.

Table 1. Sensor Data Acquired by ARM Cortex M4

\begin{tabular}{|c|c|c|c|}
\hline $\begin{array}{c}\text { Sl } \\
\text { No }\end{array}$ & $\begin{array}{c}\text { Temperatur } \\
\text { e Sensor } \\
\text { Data }\end{array}$ & pH Sensor Data & $\begin{array}{c}\text { Depth sensor } \\
\text { Data }\end{array}$ \\
\hline 1 & 28.30000000 & 7 & 0.60000000000 \\
\hline 2 & 28.20000000 & 7.10000000000000 & 0.50000000000 \\
\hline 3 & 28.30000000 & 7 & 0.90000000000 \\
\hline 4 & 28.30000000 & 6.90000000000000 & 1 \\
\hline 5 & 28.30000000 & 7.10000000000000 & 1.20000000000 \\
\hline 6 & 28.40000000 & 7.10000000000000 & 1.60000000000 \\
\hline 7 & 28.40000000 & 7.20000000000000 & 1.40000000000 \\
\hline 8 & 28.40000000 & 7.20000000000000 & 1.20000000000 \\
\hline 9 & 28.40000000 & 7.20000000000000 & 1.10000000000 \\
\hline 10 & 28.40000000 & 7.10000000000000 & 1.70000000000 \\
\hline 11 & 28.40000000 & 7.20000000000000 & 1.80000000000 \\
\hline 12 & 28.30000000 & 7.20000000000000 & 1.90000000000 \\
\hline 13 & 27.90000000 & 7.20000000000000 & 1.10000000000 \\
\hline 14 & 27.90000000 & 7.30000000000000 & 0.70000000000 \\
\hline 15 & 27.90000000 & 7.30000000000000 & 0.60000000000 \\
\hline
\end{tabular}

The number of errors when the acquired temperature data,ph data and depth data is passed through FFT ,DWT and DTCDWT in AWGN and Acoustic noise is tabulated in the table 2,table 3 and table 4 for SNR from 0 to 50 . environments (AWGN and Acoustic Channel). The data transmission unit, channel and BER calculation. The

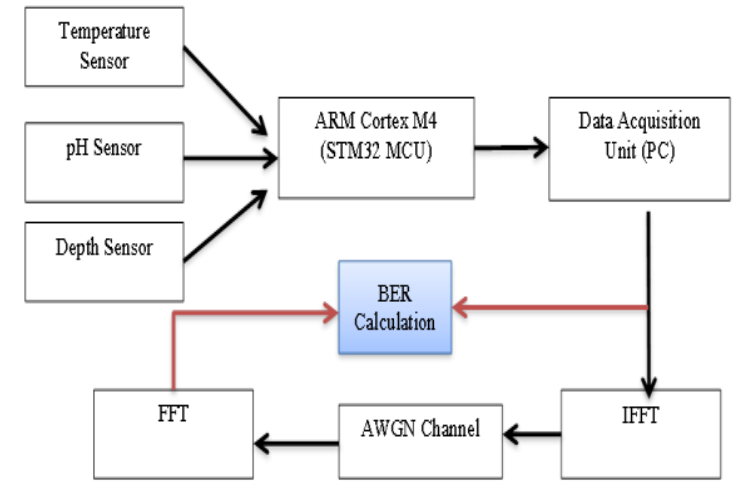

Figure.2. FFT based Sensor Data Processing system in AWGN Channel

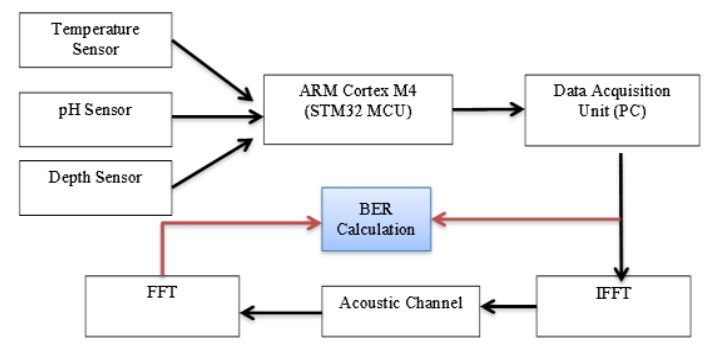

Figure.3. FFT based Sensor Data Processing system in Acoustic Channel

The Figure 4 and figure 5 shows the sensor data transmission unit, DWT/IDWT based Sensor data transmission unit in AWGN and Acoustic channel.

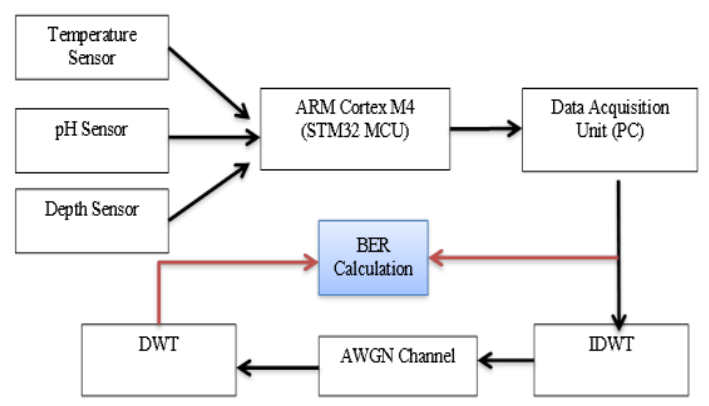

Figure.4. DWT based Sensor Data Processing system in AWGN Channel

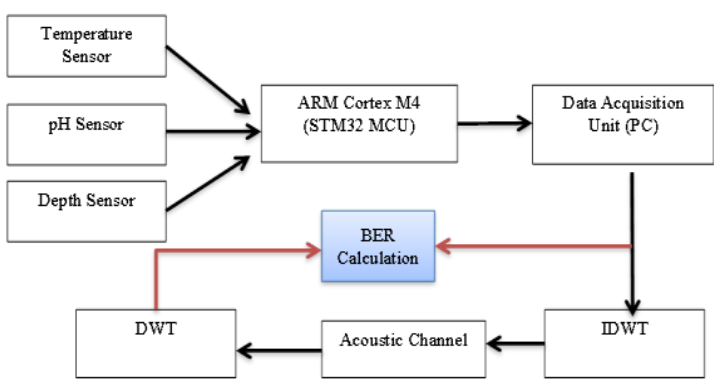

Figure.5. DWT based Sensor Data Processing system in Acoustic Channel

The Figure 6 and figure 7 shows the sensor data transmission unit, 


\begin{tabular}{|c|c|c|c|c|c|c|c|}
\hline \multicolumn{9}{|c|}{ Parameter = Temperature : 26-30 C } & \multicolumn{2}{c|}{ Number of Acquired Sensor Data = 64 } \\
\hline SI No & SNR & $\begin{array}{c}\text { Number of } \\
\text { Errors in } \\
\text { FFT with } \\
\text { AWGN }\end{array}$ & $\begin{array}{c}\text { Number of } \\
\text { Errors in FFT } \\
\text { with AWGN } \\
\text { and Acoustic } \\
\text { Noise }\end{array}$ & $\begin{array}{c}\text { Number of } \\
\text { Errors in } \\
\text { DWT with } \\
\text { AWGN }\end{array}$ & $\begin{array}{c}\text { Number of } \\
\text { Errors in DWT } \\
\text { AWGN and } \\
\text { Acoustic Noise }\end{array}$ & $\begin{array}{c}\text { Number of } \\
\text { Errors in } \\
\text { DTCDWT } \\
\text { with AWGN }\end{array}$ & $\begin{array}{c}\text { Number of } \\
\text { Errors in } \\
\text { DTCDWT } \\
\text { with AWGN } \\
+ \text { Acoustic } \\
\text { Noise }\end{array}$ \\
\hline 1 & 0 & 71.55 & 482509.83 & 59.382 & 46142.761 & 0.852 & 11457.95 \\
\hline 2 & 10 & 17.93 & 198942 & 14.53 & 17463.63 & 0.82 & 11371.78 \\
\hline 3 & 20 & 5.1894 & 57382.9 & 3.867 & 6481.76 & 0.8294 & 11520 \\
\hline 4 & 30 & 2.27 & 23997.32 & 1.35 & 2385.53 & 0.8279 & 11434.99 \\
\hline 5 & 40 & 0.70 & 22799.19 & 0.54 & 989.81 & 0.829 & 11451.98 \\
\hline 6 & 50 & 0.17678 & 20319.3 & 0.171 & 606.07 & 0.83 & 11461.65 \\
\hline
\end{tabular}

in AWGN and Acoustic channel.

system in Acoustic Channel

\begin{tabular}{|c|c|c|c|c|c|c|c|}
\hline \multicolumn{4}{|c|}{ Parameter $=$ Ph 6.0-8.0 ppm } & \multicolumn{3}{|c|}{ Number of Acquired Sensor Data $=64$} & \multirow[b]{2}{*}{$\begin{array}{c}\text { Number of } \\
\text { Errors in } \\
\text { DTCDWT } \\
\text { with AWGN } \\
+ \text { Acoustic } \\
\text { Noise }\end{array}$} \\
\hline SI No & SNR & $\begin{array}{c}\text { Number of } \\
\text { Errors in FFT } \\
\text { with AWGN }\end{array}$ & $\begin{array}{c}\text { Number of } \\
\text { Errors in FFT } \\
\text { with AWGN } \\
\text { and Acoustic } \\
\text { Noise }\end{array}$ & $\begin{array}{c}\text { Number of } \\
\text { Errors in } \\
\text { DWT with } \\
\text { AWGN }\end{array}$ & $\begin{array}{c}\text { Number of } \\
\text { Errors in } \\
\text { DWT AWGN } \\
\text { and Acoustic } \\
\text { Noise }\end{array}$ & $\begin{array}{c}\text { Number of } \\
\text { Errors in } \\
\text { DTCDWT } \\
\text { with AWGN }\end{array}$ & \\
\hline 1 & 0 & 15.057 & 163280.83 & 13.63 & 13983.85 & 0.237 & 5620.73 \\
\hline 2 & 10 & 4.8806 & 55112.27 & 3.8953 & 3727.042 & 0.230 & 5295.94 \\
\hline 3 & 20 & 1.755 & 22834.24 & 1.5865 & 1759.00 & 0.215 & 5282.17 \\
\hline 4 & 30 & 0.490 & 21666.38 & 0.43 & 782.02 & 0.217 & 5317.22 \\
\hline 5 & 40 & 0.1739 & 20386.0 & 0.1276 & 555.154 & 0.216 & 5316.0 \\
\hline 6 & 50 & 0.044952 & 20229.052 & 0.0422 & 495.72 & 0.210 & 5320.60 \\
\hline
\end{tabular}

\begin{tabular}{|c|c|c|c|c|c|c|c|}
\hline \multicolumn{9}{|c|}{ Parameter = Water Depth (0-4m ) } & \multicolumn{2}{c|}{ Number of Acquired Sensor Data = 64 } \\
\hline SI No & SNR & $\begin{array}{c}\text { Number of } \\
\text { Errors in FFT } \\
\text { with AWGN }\end{array}$ & $\begin{array}{c}\text { Number of } \\
\text { Errors in FFT } \\
\text { with AWGN } \\
\text { and Acoustic } \\
\text { Noise }\end{array}$ & $\begin{array}{c}\text { Number of } \\
\text { Errors in } \\
\text { DWT with } \\
\text { AWGN } \\
\text { EWmber of } \\
\text { Errors in } \\
\text { DWT AWGN } \\
\text { and Acoustic } \\
\text { Noise }\end{array}$ & $\begin{array}{c}\text { Number of } \\
\text { Errors in } \\
\text { DTCDWT } \\
\text { with AWGN }\end{array}$ & $\begin{array}{c}\text { Number of } \\
\text { Errors in } \\
\text { DTCDWT } \\
\text { with AWGN } \\
+ \text { Acoustic } \\
\text { Noise }\end{array}$ \\
\hline 1 & 0 & 4.3077 & 423240.15 & 3.769 & 27973.92 & 0.17879 & 4626.65 \\
\hline 2 & 10 & 1.092 & 168900.94 & 1.0626 & 14714.90 & 0.081997 & 3858.97 \\
\hline 3 & 20 & 0.39322 & 21072.85 & 0.368 & 6247.86 & 0.0779 & 3806.66 \\
\hline 4 & 30 & 0.1234 & 20703.96 & 0.0843 & 5414.56 & 0.0575 & 3754.77 \\
\hline 5 & 40 & 0.0363 & 20423.42 & 0.03609 & 4768.56 & 0.0589 & 3745.89 \\
\hline 6 & 50 & 0.011185 & 20262.60 & 0.00894 & 4566.24 & 0.0573 & 3743.05 \\
\hline
\end{tabular}

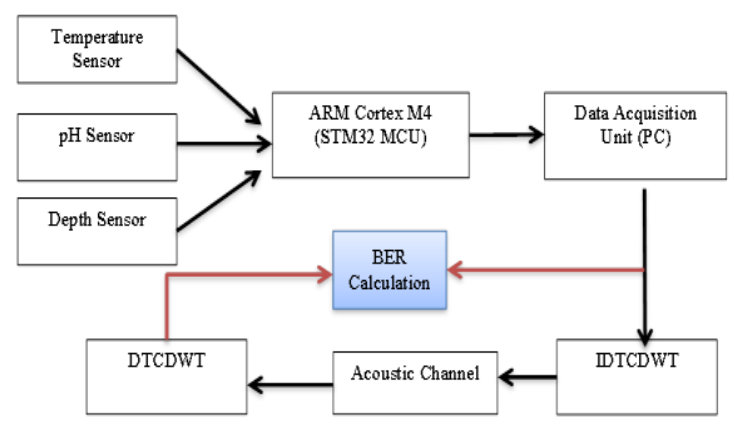




\section{THE EFFECTIVE TRANSMISSION OF ACQUIRED SENSOR DATA WITH FFT, DWT AND DTCWT IN DIFFERENT CHANNEL ENVIRONMENT}

such has temperature, $\mathrm{pH}$ and Depth processed using FFT,DWT and DTCDWT in AWGN and Acoustic Channel.

\section{A. Temperature sensor data Processing}

The Figure below shows the GUI for FFT,DWT and DTCDWT in AWGN channel and Acoustic channel for Acquired temperature data with number of sensor data considered are 64 and SNR of 0 and 50.

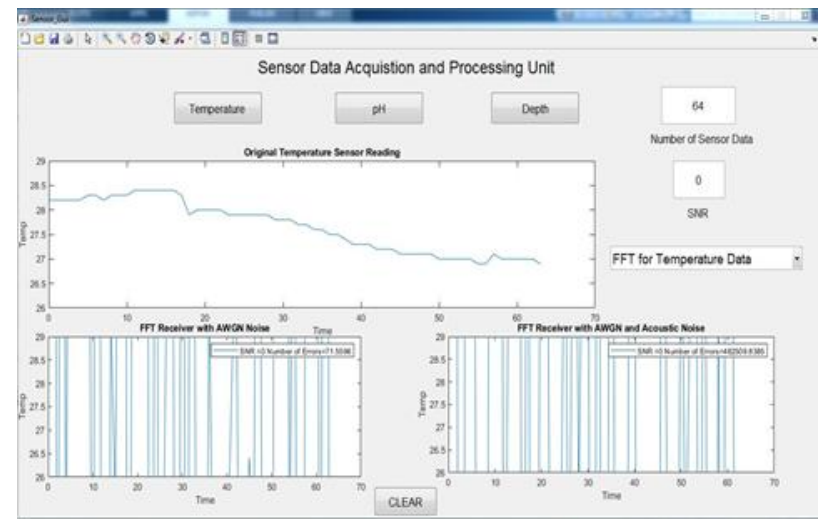

Figure.7. GUI for Temperature Sensor data in FFT with SNR=0

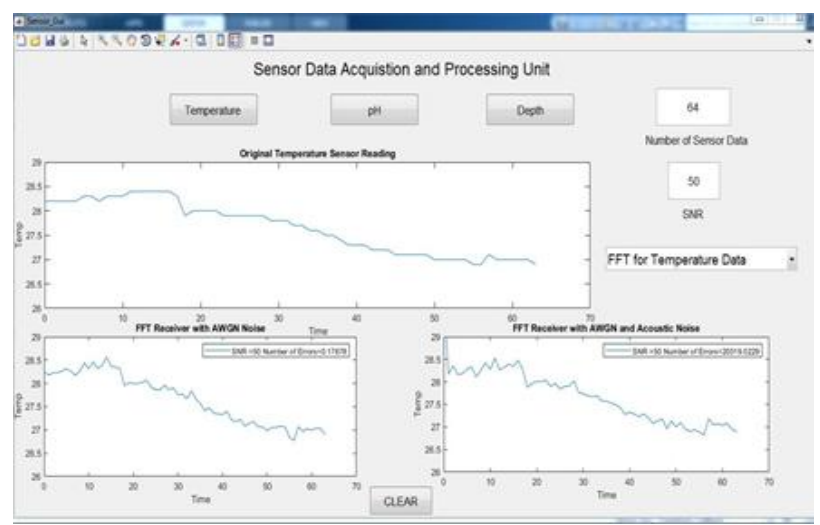

Figure.8. GUI for Temperature Sensor data in FFT with $\mathbf{S N R}=\mathbf{5 0}$

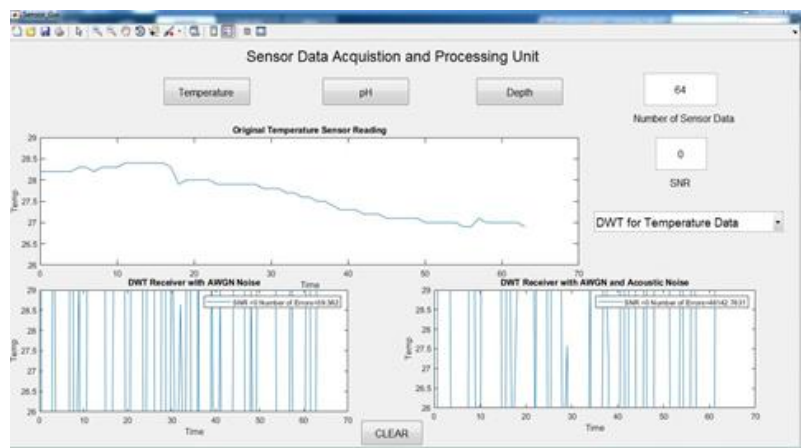

Figure.9. GUI for Temperature Sensor data in DWT with SNR=0

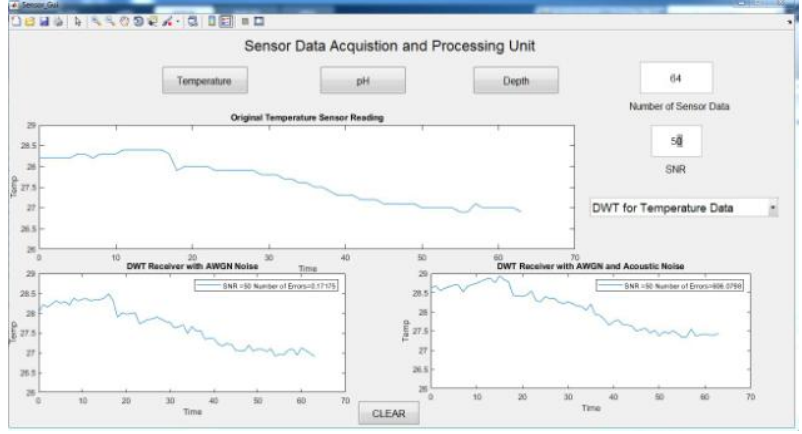

Figure.10. GUI for Temperature Sensor data in DWT with

$\mathrm{SNR}=\mathbf{5 0}$

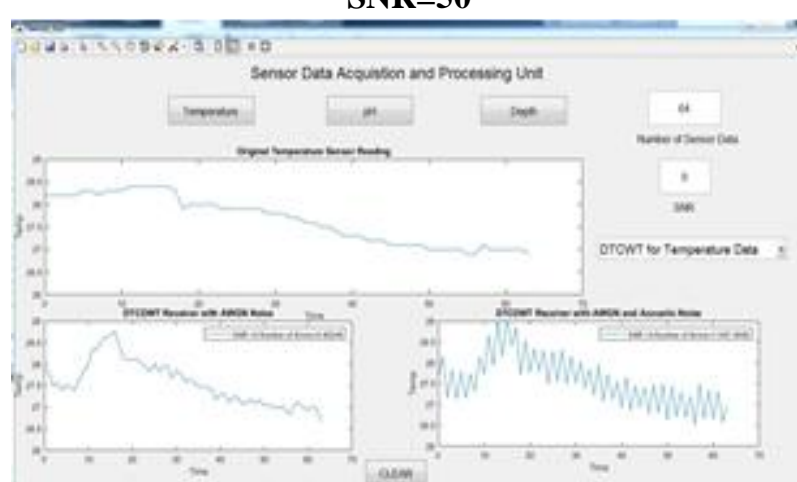

Figure.11. GUI for Temperature Sensor data in DTCDWT with SNR=0

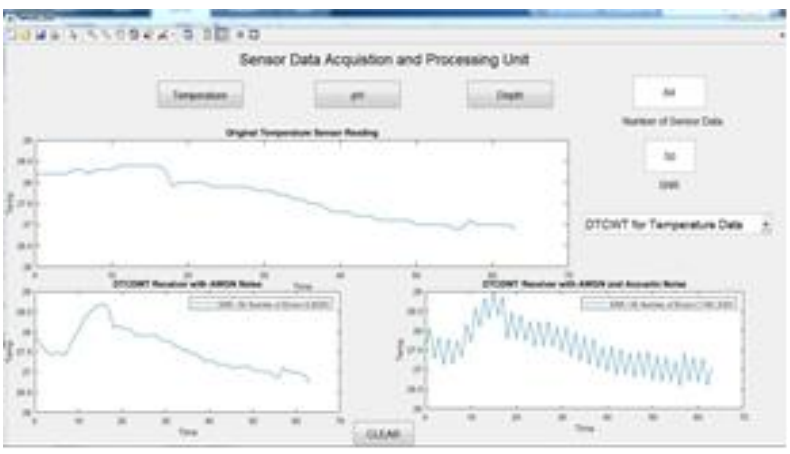

Figure.12. GUI for Temperature Sensor data in DTCDWT with $\mathrm{SNR}=50$

\section{B. pH sensor data Processing}

The Figure below shows the GUI for FFT, DWT and DTCDWT in AWGN channel and Acoustic channel for Acquired $\mathrm{pH}$ data with number of sensor data considered are 64 and SNR of 0 and 50.

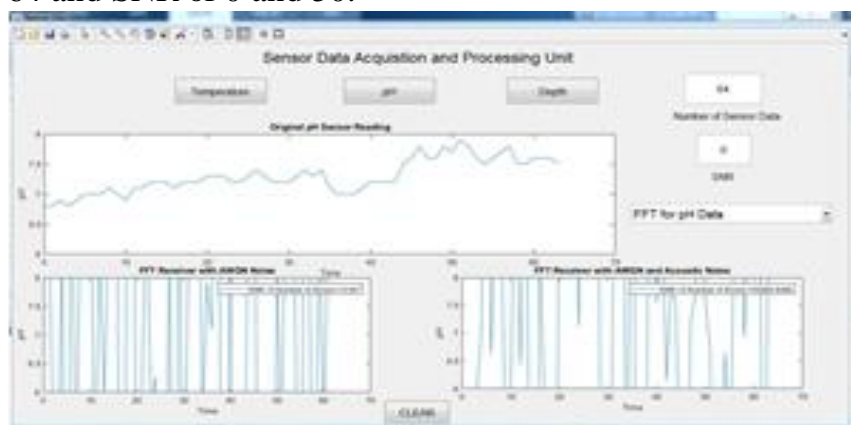

Figure.13. GUI for pH Sensor data in FFT with $\mathrm{SNR}=0$

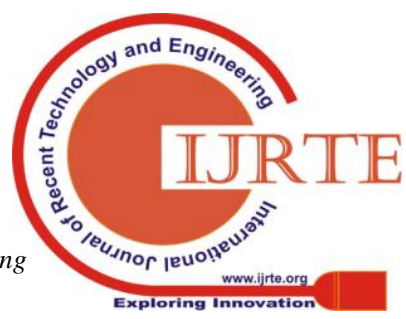




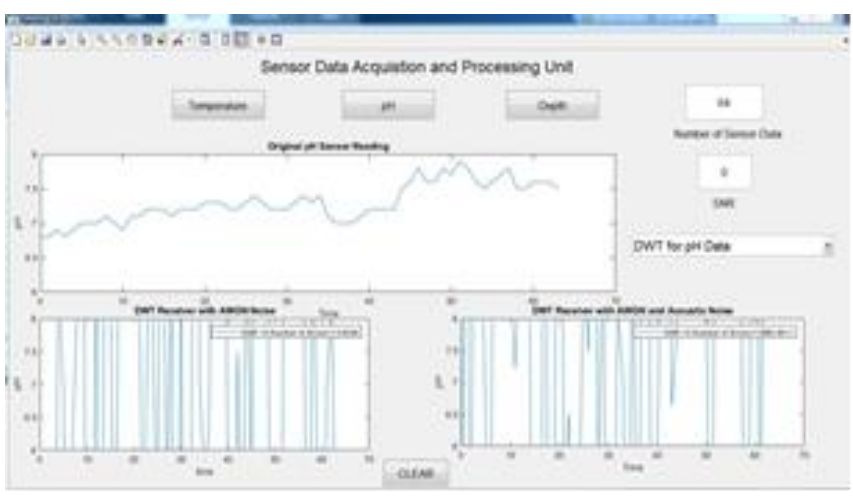

Figure.14. GUI for pH Sensor data in DWT with

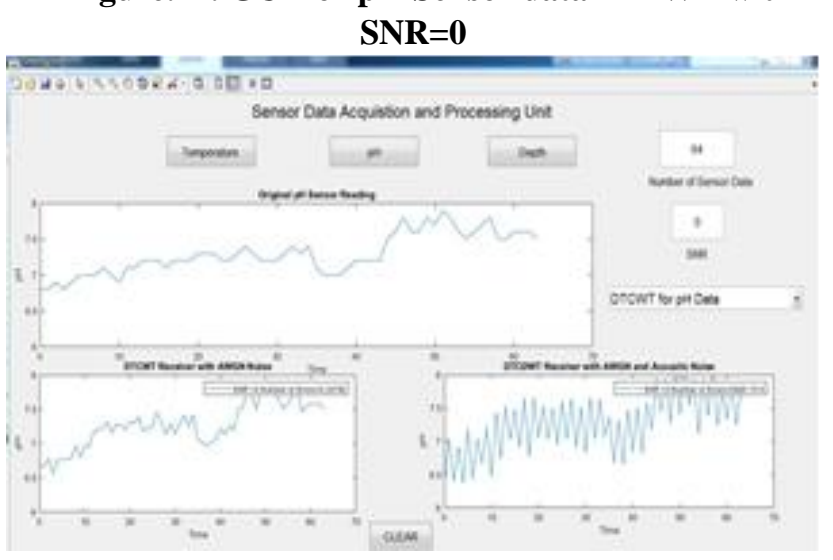

Figure.15. GUI for $\mathrm{pH}$ Sensor data in DTCDWT with $\mathrm{SNR}=\mathbf{0}$

\section{Depth sensor data Processing}

The Figure below shows the GUI for FFT,DWT and DTCDWT in AWGN channel and Acoustic channel for Acquired depth data with number of sensor data considered are 64 and SNR of 0 and 50.

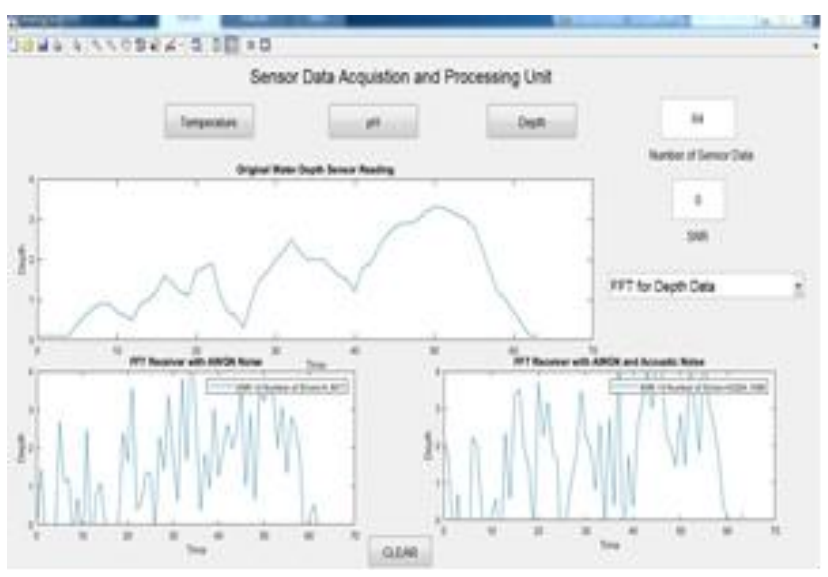

Figure.16. GUI for depth Sensor data in FFT with $\mathrm{SNR}=0$

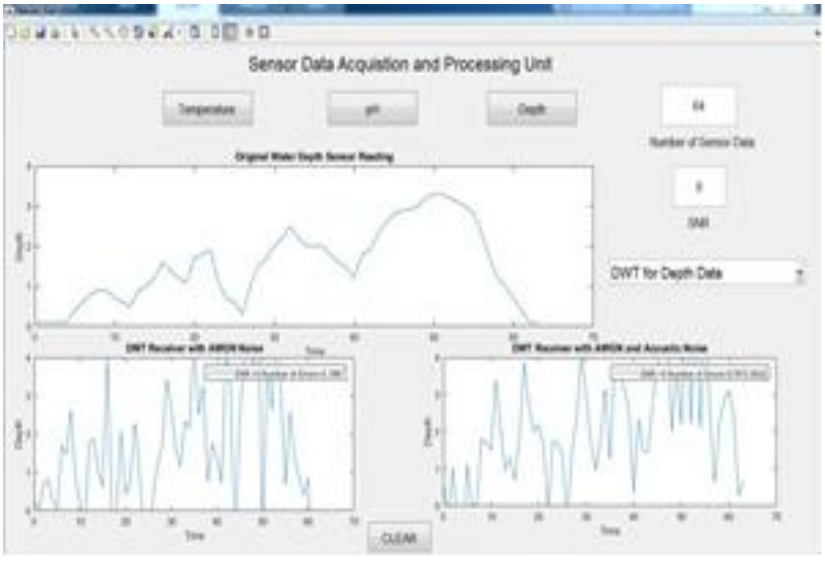

Figure.17. GUI for depth Sensor data in DWT with $\mathbf{S N R}=\mathbf{0}$

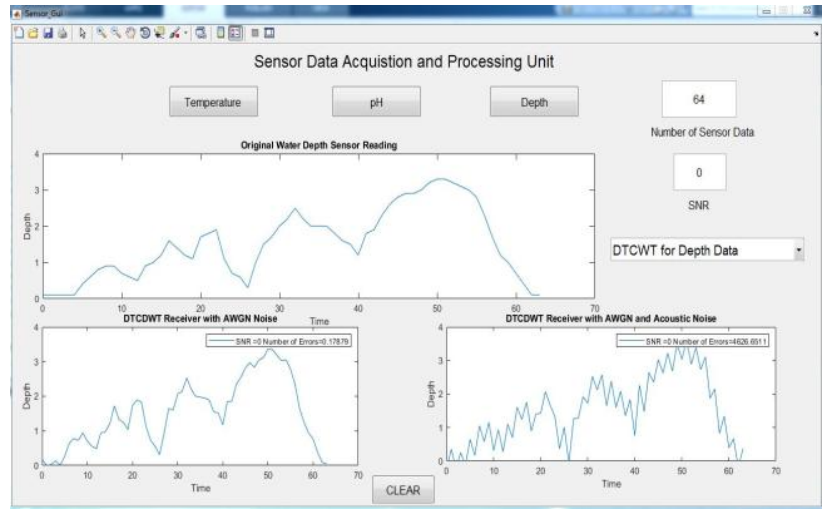

Figure.18. GUI for depth Sensor data in DTCDWT with $\mathrm{SNR}=0$

The comparison of temperature sensor, depth sensor and $\mathrm{pH}$ sensor with different SNR ranging from 0 to 50 with 64 numbers of samples considered.

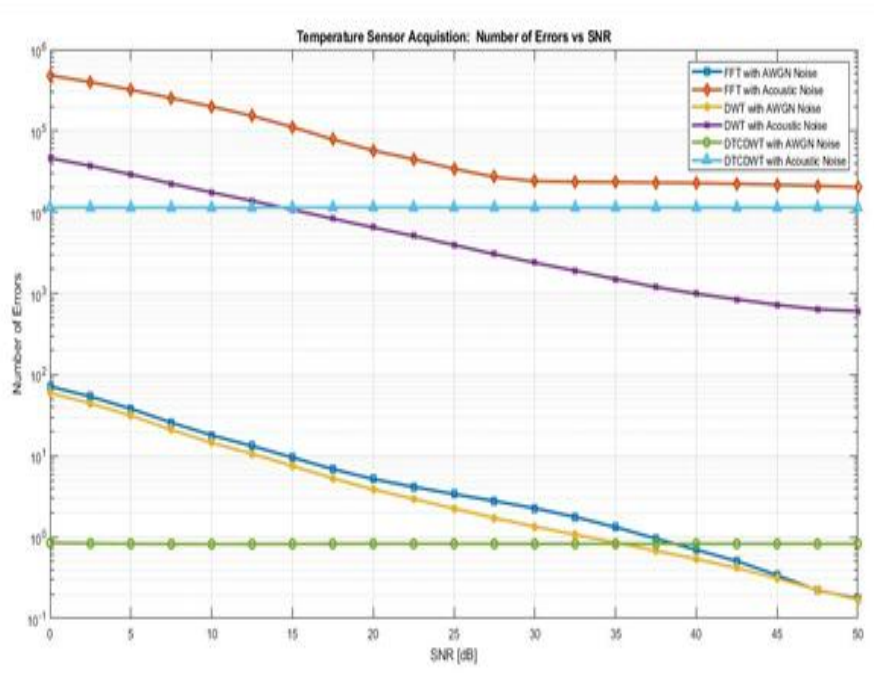

Figure.19. Comparison of Temperature Sensor Acquisition with AWGN and Acoustic Channel

Published By: 


\section{THE EFFECTIVE TRANSMISSION OF ACQUIRED SENSOR DATA WITH FFT, DWT AND DTCWT IN DIFFERENT CHANNEL ENVIRONMENT}

\section{ACKNOWLEDGEMENT}

We would like to thank Dr.Sreerama Reddy G.M,

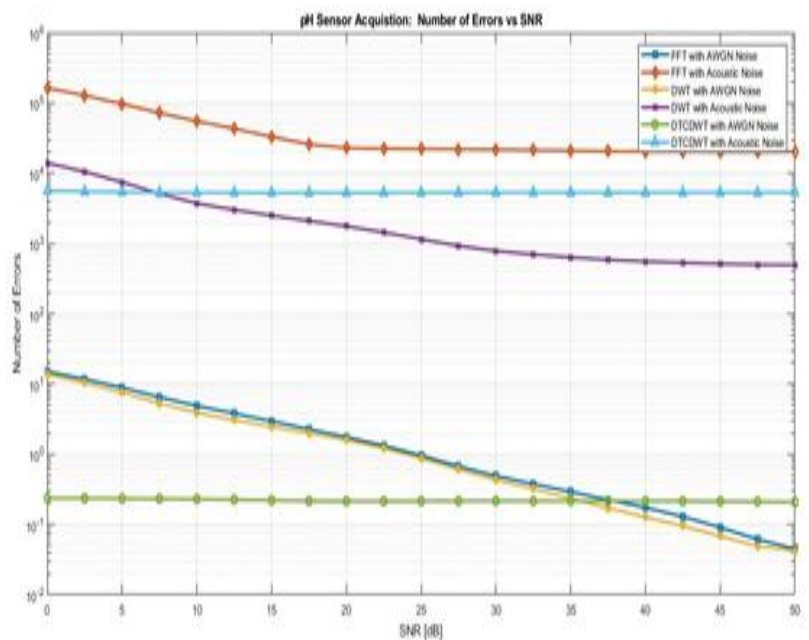

A WG Giv ana Acoustic Cnannel

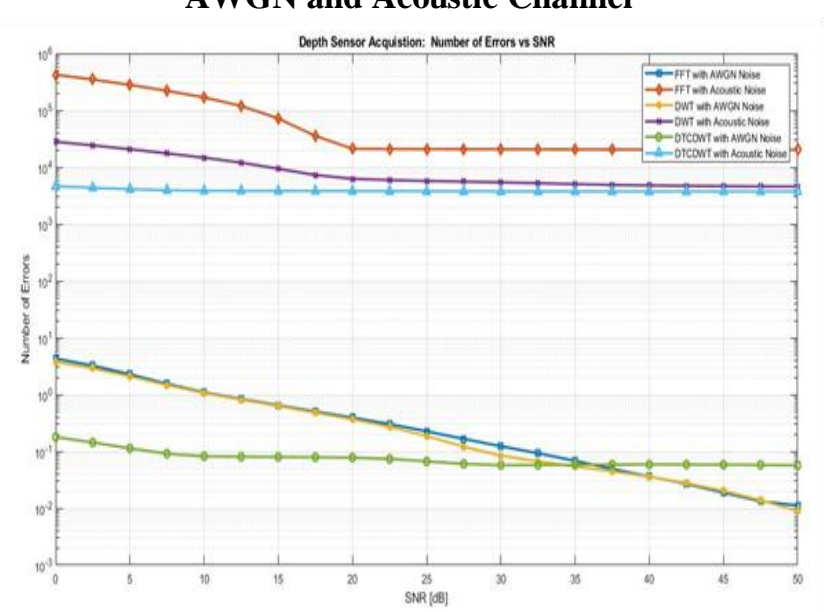

Figure.21. Comparison of depth Sensor Acquisition with AWGN and Acoustic Channel

Comparison results shows that the number of errors in the case of DTCDWT is less when compared to DWT and FFT in all the acquired sensor values and also we can notice that in acoustic channel number of errors are increased all the three cases and is slightly reduced in the case of DTCDWT.

\section{CONCLUSION}

The analysis of FFT, DWT and DTCDWT for efficient transmission of real time sensor data in different channel environment such as AWGN and Acoustic Channel has been achieved. The simulation results show that number of errors in the case of DTCDWT is less compared to DWT and FFT for all the acquired sensor values. The number of errors is more in acoustic channel because of thermal noise, shipping noise, wave noise and other additional noise factors. The real time underwater sensor data is acquired for one hour duration. The three sensor data like temperature sensor data, pH Sensor data, depth sensor data are acquired and processed using FFT, DWT and DTCDWT. The simulation is done using MATLAB GUI for the real sensor data which was acquired. Implementation of the same work was carried out using STM32 Microcontroller Boards.
Principal, C Byregowda institute of Technology, kolar for his support and guidance for successfully completion of the research objective. We would like to thank faculty members of CBIT, kolar and NHCE, Bangalore for there support in preparing the paper and providing tools needed for obtaining the results.

\section{REFERENCES}

1. Naveen H, Dr.Sreerama Reddy G M," Development of OFDM based data acquisition System from underwater acoustic sensors", IEEE Conference, ISSN 0973-7529; ISBN 978-93-80544-28-1,pp 3842-3847 (2018).

2. Naveen H, Dr.Sreerama Reddy G M, "Performance analysis of FFT based OFDM and DWT based OFDM for Underwater Acoustic Communication", Indian Journal of Science and Technology, Vol 10(36), September 2017.

3. Naven H, Dr.Sreerama Reddy G M, 'High Speed OFDM based Image transmission system for Remotely Operated Underwater Vehicle (ROV)', International Journal of Pure and Applied Mathematics, Vol 117, No.20, 2017, pp 959-970.

4. Diogo Mendes, A MATLAB/Simulink model to evaluate underwater acoustic. Masters thesis, Universidade do Minho, Portugal, December (2011)

5. Kalangi Pullarao Prasanth. Modelling and simulation of an underwater acoustic communication channel. Masters thesis, University of applied sciences Bremen, Germany, (2004).

6. M. Stojanovic. Recent advances in high-speed underwater acoustic communications. Oceanic Engineering, IEEE Journal of, 21(2):125136, (1996).

7. Dario Pompili and Ian F. Akyildiz. Overview of networking protocols for underwater wireless communications. Comm. Mag., 47(1):97102, January (2009).V. K. Singh, "Discrete wavelet transform based image compression", International Journal of Remote Sensing, 2014.

8. Anitha K, Dharmistan K, Varugheese, Dr Muniraj NJR. Modified Lifting Based DWT/IDWT Architecture for OFDM on Virtex-5 FPGA. ISSN 2249-4596(2012).

9. Veena MB, Shanmukha Swamy MN. Performance analysis of DWT based OFDM over FFT based OFDM and implementing on FPGA. International Journal of VLSI design \& Communication Systems (VLSICS). 2011 September.

10. Seok Joong Hwang, Youngsun Han, Seok Wook Kim, Jongsun Park Resource efficient Implementation of Low power MB-OFDM PHY Baseband modem with highly parallel architecture . IEEE Trans. Very large scale integration system. 2012 July; 20:7.James S. Walker, "Wavelet -based Image Compression", Sub-chapter of CRC Press book: Transforms and Data Compression.

11.Christos Chrysafis and Antonio Ortega, "Line-Based, Reduced Memory, Wavelet Image Compression”, IEEE transactions on image processing, vol. 9, no. 3, march 2000.

12.Baosheng Li, Shengli Zhou, Milica Stojanovic, Lee Freitag, and Peter Willett. Multicarrier Communication over Underwater Acoustic Channels with Non uniform Doppler Shifts. IEEE Journal Of Oceanic Engineering. 2008

13. Yimin Shi, Zhankui Cao, Haichao Wei, Sihai Zhang, Wuyang Zhou DSP Implementation of OFDM-based Underwater Acoustic Communication Transceiver IEEE. 2014

14. Marcelo J. Weinberger, Senior Member, IEEE, Gadiel Seroussi, Fellow, IEEE, and Guillermo Sapiro, Member, IEEE, "The LOCO-I Lossless Image Compression Algorithm: Principles and Standardization into JPEG-LS",IEEE transactions on Image Processing, vol. 9, no. 8, August 2000. 